\title{
Influências do PIBID no conceito e na efetividade da qualidade em educação
}

\author{
Influences of PIBID in concept and effectiveness of quality in education
}

Nathália Cristina Amorim Tamaio de Souza ${ }^{1}$

\section{Resumo}

Delinear caminhos para assegurar o direito à qualidade na educação implica, necessariamente, pensar desde sua configuração conceitual até sua perspectiva pragmática, ou seja, a qualidade enquanto prática social concreta. Nessa direção, e tendo em vista a pluralidade de sentidos que se confere à qualidade no âmbito educacional, este artigo apresenta um dos olhares possíveis para a compreensão desse tema tão necessário quanto complexo. Tendo como pano de fundo o pressuposto de que a qualificação da formação docente é condição fundamental para a elevação do desempenho escolar, e como referencial teórico os estudos que consubstanciam o conceito de professor-reflexivo, são descritas e analisadas as influências do programa PIBID na concepção e na efetividade da qualidade em educação, a partir do estudo dos documentos oficiais sobre o programa e de relatos de bolsistas de um subprojeto de Pedagogia. Como uma das principais inferências, a pesquisa revela a existência de um conceito de qualidade evidenciado no desenvolvimento diário dos alunos, na incorporação de um conjunto de aptidões que transcendem os indicadores de avaliações externas e na transformação das práticas dos professores e futuros professores.

Palavras-chave: Qualidade em educação. PIBID. Educação Básica. Formação de professores.

\begin{abstract}
Delineating ways to ensure the right to quality in education necessarily implies thinking from its conceptual configuration to its pragmatic perspective, that is, quality as a concrete social practice. In this direction, and in view of the plurality of meanings conferred to quality in the educational field, this article presents one of the possible perspectives for understanding this theme, both necessary and complex. Against the background of the assumption that the qualification of teacher education is a fundamental condition for raising school performance, and as a theoretical reference the studies that substantiate the concept of reflective teacher, the influences of the PIBID program in the conception are described and analyzed. and in the effectiveness of quality
\end{abstract}

\footnotetext{
${ }^{1}$ Pedagoga e Mestra em Educação Escolar pela Universidade Estadual Paulista (UNESP), e Doutoranda em Educação na Universidade Estadual de Campinas (UNICAMP). Professora de Educação Básica na escola SESI de Araraquara e integrante dos grupos de pesquisa: Alfabetização, Leitura e Escrita/Trabalho Docente na Formação Inicial (ALLE/AULA), da FE/UNICAMP; Letramento do Professor, do IEL/UNICAMP; e Grupo de Estudos e Propostas sobre Formação do Educador Contemporâneo (GEPFEC) da FCLAr/UNESP. Email: nathytamaio@hotmail.com
} 


\section{-Revista de Iniciação à Docência, v.6, n.2, 2021- \\ Publicação: dezembro, 2021 - ISSN 2525-4332}

in education, based on the study of official documents about the program and the reports of fellows from a sub-project of Pedagogy. As one of the main conclusions, the research reveals the existence of a concept of quality evidenced in the daily development of students, in the incorporation of a set of skills that transcend the indicators of external evaluations, and in the transformation of the practices of teachers and future teachers.

Key words: Quality in Education. PIBID. Basic Education. Teacher Training.

\section{Introdução}

Analisar a qualidade na Educação Básica a partir de diferentes dimensões, isto é, considerando seus aspectos político, legislativo e filosófico, tem sido uma tarefa constante de vários pesquisadores. $O$ alto percentual de pesquisas que se debruçam nesse tema talvez possa ser justificado pela busca de definição ou explicação de um fenômeno que, historicamente, sofre mudanças quanto ao seu conceito e quanto ao que se espera e que se alcança em termos de sua efetividade.

Muito se fala a respeito do direito a uma educação de qualidade. Em capítulo específico sobre a educação, pode-se ler no Art. 206, inciso VII da Constituição da República de 1988, que o ensino será ministrado com base no princípio de padrão de qualidade.

No entanto, a definição da qualidade que buscamos atingir na educação ainda é algo pouco tangível e claro. Conforme ressalta Cury (2010, p. 21), "o retrato mais difundido até agora em torno da qualidade em educação escolar é de um quadro negativo indicando muito mais o que a qualidade não é do que aquilo que ela deve ser". Estaríamos pensando em uma qualidade (ou na falta dela) pautada no rendimento escolar demonstrado nos resultados das avaliações externas? Uma qualidade que aponta para a capacidade de atingir ou não uma finalidade? De que qualidade falamos, afinal?

Visando contribuir a compreensão da última questão, neste artigo desenvolvo um recorte focal, tecendo uma análise sobre o conceito de qualidade em educação que permeia a proposta e as ações do Programa Institucional de Bolsa de Iniciação à Docência (PIBID), bem como sobre os indícios de sua efetividade no interior das escolas parceiras vinculadas a esse programa. Para tanto, apoio-me no pressuposto de que a qualidade da educação depende, em grande medida, da elevação da qualificação de docentes, mais especificamente no período da formação inicial, e da articulação entre as competências adquiridas no âmbito da universidade e no meio escolar de forma que uma esteja constantemente ancorada na outra.

Ao pensar no percurso metodológico que subsidiaria este trabalho, levantei o seguinte questionamento: como seria possível prever a legitimidade de uma ação que envolve pessoas senão pela riqueza de informações concedidas por aqueles que estão diretamente envolvidos? Destarte, a presente pesquisa contou, num primeiro momento, 


\section{-Revista de Iniciação à Docência, v.6, n.2, 2021- \\ Publicação: dezembro, 2021 - ISSN 2525-4332}

com um levantamento documental, cuja análise teve como cerne a discussão do referencial teórico que orienta o PIBID, apresentando como fonte primária a legislação e os documentos produzidos pelos órgãos oficiais. O segundo momento deste trabalho configura-se pelo estudo de um subprojeto do PIBID vinculado ao curso de Pedagogia de uma universidade pública do interior paulista. Tal estudo ${ }^{2}$ inclui uma entrevista sistematizada em artigo, o detalhamento do mencionado subprojeto elaborado pelo coordenador, e um conjunto de informações oriundas de dois anos de seleção, organização e descrição, que integram relatórios semestrais e atas de reuniões.

\section{PIBID: por que, para quem e para quê?}

Os cursos de licenciatura no Brasil têm sido alvos constantes de uma sobreposição de medidas de intervenção e isto se deve à constatação de que a formação inicial não vem oferecendo aos licenciandos os subsídios necessários para enfrentarem os desafios da atividade docente.

Pesquisas que contemplam o assunto (GATTI; BARRETO; ANDRÉ, 2011; GATTI; NUNES, 2008) revelam que os cursos mantêm modelos idealizados de escola, de alunos e de ensino e se concentram no exercício de uma reflexão de caráter pessoal sobre a própria prática do licenciando, num esforço isolado do contexto em que se dará essa prática, além de apresentarem currículos fragmentários, e predominância dos estudos teóricos.

Os mencionados autores acreditam que este modelo de formação tem se mostrado ineficaz, ou seja, a concepção tradicional de formação inicial de professores em forma teórica dissociada de experiências e conhecimentos adquiridos pela prática não responde às necessidades reais que a contemporaneidade coloca.

Com o intuito de alterar positivamente esse quadro, ações políticas têm fomentado programas com características diferenciadas, entre os quais se destaca o PIBID. Compondo um conjunto de ações vinculadas à Política Nacional de Formação de Profissionais do Magistério da Educação Básica, o PIBID alcançou significativa adesão em nível nacional.

Segundo estudo realizado por André (2012), direcionado inicialmente às instituições federais de ensino superior e atendendo cerca de 3 mil bolsistas em 2007, o PIBID expandiu-se rapidamente, incluindo universidades públicas estaduais, municipais e comunitárias, abrangendo todas as licenciaturas, chegando, em 2011 a quase 30 mil bolsistas, de 146 Instituições de Ensino Superior (IEs). Deimling e Reali (2020) atualizam os dados quantitativos, informando que, em 2014, 284 IEs de todo o País participavam do PIBID desenvolvendo 313 projetos de iniciação à docência em mais de 5 mil escolas

\footnotetext{
${ }^{2}$ Cumpre informar que o estudo, por envolver seres humanos, foi devidamente encaminhado e aprovado pelo Comitê de Ética em Pesquisa Local (CEP - UNESP - FCL/Ar). Número CAAE: 17231613.2.0000.5400.
} 
públicas de Educação Básica, e, em 2016, o número de bolsas ativas no Programa alcançou o total de 72.057, distribuídas entre estudantes de licenciatura, professores da educação básica e professores do ensino superior. Em 2018, o PIBID passou por uma reformulação pela Portaria Gab n 45, de 12 de março de 2018 (BRASIL, 2018), passando a atuar em colaboração ao Programa de Residência Pedagógica (PRP).

A iniciativa PIBID trata-se de uma ação da Coordenação de Aperfeiçoamento de Pessoal de Nível Superior (CAPES) em conjunto com a Secretaria de Educação Superior (SESu/MEC) e o Fundo Nacional de Desenvolvimento da Educação (FNDE). Um programa com características transformadoras que alcançou, ao longo de sua existência, significativa aderência em nível nacional e que, de acordo com o Edital $^{3}$ que o regulamenta, tem como objetivos promover a melhoria da qualidade da Educação Básica, incentivar a formação de professores para a Educação Básica, valorizar o magistério, promover a articulação integrada da Educação Superior com a Educação Básica do sistema público, elevar a qualidade das ações acadêmicas voltadas à formação inicial de professores nos cursos de licenciatura, estimular a integração da Educação Superior com a Educação Básica no ensino fundamental e médio, fomentar experiências metodológicas e práticas docentes de caráter inovador, que se orientem para a superação de problemas identificados no processo ensino-aprendizagem, valorizar o espaço da escola pública como campo de experiência para a construção do conhecimento na formação de professores para a Educação Básica, e proporcionar aos futuros professores participação em ações, experiências metodológicas e práticas docentes articuladas com a realidade local da escola.

Apesar de o PIBID ser um programa extracurricular que não compreende a totalidade dos estudantes de licenciatura, ele representa uma das mais importantes ações governamentais no sentido de melhorar a qualidade da formação de professores e, consequentemente, da educação de modo geral. Desse modo, as perguntas que movem este trabalho são: o que é uma educação de qualidade na perspectiva do PIBID? O que dizem a literatura e os bolsistas de um subprojeto do curso de Pedagogia sobre a efetividade da qualidade da educação a partir das ações empreendidas pelo PIBID? Tais questões são exploradas nas seções a seguir.

\section{A qualidade da formação como condição para a qualidade da educação}

Quando tratamos das dificuldades e dos entraves que nos impossibilitam de atingir os "padrões mínimos de qualidade na educação", conforme descrito na Lei de Diretrizes e Bases da Educação Nacional (LDBEN, 1996), tendemos a responsabilizar os velhos problemas brasileiros. Esses problemas podem ser decorrentes, entre outros fatores, da falta de infraestrutura das escolas, da desvalorização da profissão docente, da

\footnotetext{
3 Trata-se do Edital MEC/CAPES/FNDE de seleção pública de propostas de projetos de iniciação à docência, voltados ao Programa Institucional de Iniciação à Docência (PIBID), de 24 jan. 2008.
} 


\section{-Revista de Iniciação à Docência, v.6, n.2, 2021- \\ Publicação: dezembro, 2021 - ISSN 2525-4332}

má formação dos professores, da falta de maiores investimentos governamentais e do número elevado de alunos por professor.

Dentre os diversos desafios responsabilizados pela falta de qualidade na educação, o papel do professor assume grande importância. Diante disso, o Plano de Desenvolvimento da Educação (PDE) aponta que:

a formação inicial e continuada do professor exige que o parque de universidades públicas se volte (e não que dê as costas) para a Educação Básica. Assim, a melhoria da qualidade da Educação Básica depende da formação de seus professores, o que decorre diretamente das oportunidades oferecidas aos docentes. (BRASIL, 2007, p. 10).

Nesse contexto, o programa PIBID ganha relevo, maior projeção nacional, maiores investimentos e credibilidade do governo por apresentar-se como uma das principais iniciativas dentro da política nacional de formação de professores voltadas à superação dos percalços que afligem a docência. Conforme já mencionado, o primeiro objetivo traçado pelo programa é o de promover a melhoria da qualidade da Educação Básica, seguido da valorização e incentivo ao magistério, o que reforça uma relação direta de causa e efeito sobre a formação do professor.

Diante de tamanha proporção tomada pelo PIBID como um programa de formação de professores em nível nacional, se faz necessário questionar: que tipo de formação é proposta nesse modelo? ou ainda: o que é uma formação de qualidade dentro da perspectiva adotada por esse programa?

Para responder a essas indagações é necessário resgatar os referenciais teóricos que embasaram a construção das diretrizes do PIBID. É possível verificá-los no relatório de gestão 2009-2011 do PIBID (CAPES, 2012, p. 5) que afirma que "os princípios sobre os quais se constrói o PIBID estão de acordo com estudos sobre formação de professores de Nóvoa (2009) e de Neves (2012)" e são eles:

\footnotetext{
1. Formação de professores referenciada no trabalho na escola e na vivência de casos concretos;

2. Formação de professores realizada com a combinação do conhecimento teórico e metodológico dos professores das instituições de ensino superior e o conhecimento prático e vivencial dos professores das escolas públicas;

3. Formação de professores atenta às múltiplas facetas do cotidiano da escola e à investigação e à pesquisa que levam à resolução de situações e à inovação na educação;

4. Formação de professores realizada com diálogo e trabalho coletivo, realçando a responsabilidade social da profissão. (CAPES, 2012, p. 5).
}

Pode-se observar nos princípios do PIBID que a escola aparece como um espaço de formação dos futuros professores a partir da vivência e experimentação de casos concretos. Ou seja, há uma nítida mudança do papel da escola no PIBID, que passou a representar um espaço de formação do conhecimento prático e reflexivo, em contraposição ao modelo que concebe a escola como mero espaço de aplicação do conhecimento teórico produzido dentro dos muros das universidades. Em tais princípios, o conhecimento produzido no interior das universidades deve agir em consonância com o 


\section{-Revista de Iniciação à Docência, v.6, n.2, 2021- \\ Publicação: dezembro, 2021 - ISSN 2525-4332}

conjunto de experimentações práticas. De acordo com Nóvoa (2009), não se trata de assumir uma postura praticista da formação de professores, mas:

[...] de abandonar a ideia de que a profissão docente se define, primordialmente, pela capacidade de transmitir um determinado saber. É esta concepção que tem levado às intermináveis discussões entre republicanos, que apenas se interessariam pelos conteúdos científicos, e pedagogos, que colocariam os métodos de ensino acima de tudo o resto. (NÓVOA, 2009, p. 4).

É este sentido de aproximação e diálogo entre teoria e prática, e não uma relação de sobreposição entre os dois campos, que observamos no delineamento das ações do PIBID como basilar para o desenvolvimento de um programa de formação de professores.

Outro ponto que merece destaque, apontado nas diretrizes do PIBID, refere-se às ferramentas utilizadas para a resolução de situações e para a inovação do ensino. De acordo com as diretrizes, a investigação e a pesquisa sobre o cotidiano educacional devem ser trabalhadas na formação do professor, a fim de possibilitar ferramentas para a superação dos problemas enfrentados em sua prática profissional. Nesse aspecto, se compreende a busca pela formação do que foi denominado como professor reflexivo, isto é, a formação de um profissional que tenha capacidade de investigar e refletir sobre sua própria prática e que tenha competência de superar os problemas de seu cotidiano.

Foi ao longo da década de 1990 que se dilatou a compreensão do conceito de professor reflexivo. Segundo Pimenta (2006), dois eventos foram importantes para a divulgação do conceito de professor reflexivo no Brasil: a difusão do livro Os professores e sua formação, que traz discussões deste conceito por educadores de diversos países como Espanha, Portugal, França, Estados Unidos e Inglaterra, organizado pelo professor António Nóvoa; e a realização do I Congresso sobre Formação de Professores nos Países de Língua e Expressão Portuguesas, realizado em Aveiro, 1993, sob a coordenação da professora Isabel Alarcão.

Com relação ao conceito de professor reflexivo, este foi inspirado nos conceitos formulados por Donald Schön que, por sua vez, não escreve sua teoria pensando especificamente sobre a formação de professores, como bem pontua Alarcão (1996). Em sua pesquisa, Schön constata que a formação profissional oferecida pelas universidades estava cada vez mais voltada para si mesma, ou seja, para uma formação altamente especializada, de supervalorização das pesquisas e dos conhecimentos produzidos dentro das instituições de ensino superior. Ao mesmo tempo, o autor observa que o tipo de saber produzido nestes cursos pouco ou nada contribuía para a atuação do futuro profissional no seu campo de trabalho.

De acordo com Schön (2000, p. 20),

[...] nos últimos anos, tem havido uma crescente percepção de que os pesquisadores, que deveriam suprir as escolas profissionais com conhecimento útil, têm cada vez menos a dizer a respeito de algo que os profissionais possam considerar útil. 


\section{-Revista de Iniciação à Docência, v.6, n.2, 2021- \\ Publicação: dezembro, 2021 - ISSN 2525-4332}

O autor observa ainda que a consequência eminente desse fenômeno foi a crise de confiança no conhecimento profissional, naquele conhecimento certificado pelas instituições que detêm o poder sobre os capitais culturais objetivados em forma de diplomas, nos termos bourdiesianos. A crise de confiança acompanhada da falta de legitimidade do tipo de formação oferecida foi determinante para a construção de um novo olhar para os currículos de formação profissional.

Diante desse cenário educacional, Schön propõe repensar a formação de profissionais com base em outra lógica: na valorização da formação prática, do desenvolvimento das habilidades adquiridas na prática, habilidades que o autor denominou de "perspicácia”, "talento", “intuição” ou "talento artístico". Neste sentido, o autor afirma:

quando, nas primeiras décadas deste século, as profissões especializadas começaram a apropriar-se do prestígio da universidade, colocando nela suas escolas, "profissionalização" significava a substituição do talento artístico pelo conhecimento sistemático, de preferência científico. No entanto, com o crescimento da consciência sobre a crise de confiança no conhecimento profissional, os educadores mais uma vez começaram a ver o talento artístico como um componente essencial da competência profissional e a questionar se as faculdades fariam ou deveriam fazer qualquer coisa a respeito e, sendo assim, como a educação para o talento artístico pode ser coerente com o núcleo do currículo profissional de ciência e técnica aplicadas. (SCHÖN, 2000, p. 23).

Para Schön, a formação profissional será completa quando considerar a importância do aprendizado a partir de um contato orientado com a prática. Em outras palavras, apenas quando a instituição formadora possibilitar um contato maior de seus estudantes com a prática a ser constituída, mediado por um profissional capacitado na profissão e em um ambiente propício para o desenvolvimento do ensino, poderá haver a superação da crise de confiança instaurada na formação de futuros profissionais.

Quando se considera a formação profissional também como uma formação reflexiva sobre a prática, Schön anuncia que esta pode se desenvolver a partir de quatros conceitos: conhecimento-na-ação, reflexão-na-ação, reflexão-sobre-ação e reflexão sobre a reflexão-na-ação. A autora Alarcão (1996, p. 16) descreve tais conceitos, considerando o conhecimento-na-ação "o conhecimento que os profissionais demonstram na execução da acção; é tácito e manifesta-se na espontaneidade com que uma ação é bem desempenhada". Sobre a reflexão-na-ação e a reflexão-sobre-ação, se diferenciam pelo momento em que ocorre a reflexão, sendo que a primeira ocorre durante a prática e a segunda de um modo mais retrospectivo, após a ação. E, por fim, Alarcão (1996, p. 17) aponta que a reflexão sobre a reflexão-na-ação é um "processo que leva o profissional a progredir no seu desenvolvimento e a construir a sua forma pessoal de conhecer".

Esse conjunto de conceitos formulados por Schön a respeito de uma epistemologia da formação profissional foi amplamente difundido no campo da educação, principalmente por autores como Nóvoa (2009), Alarcão (1996), Perrenoud (1993), Zeichner (1998; 2010), entre outros. 
A proposta de formação preconizada pelo modelo do PIBID, que converge com os pressupostos teóricos apresentados, busca valorizar a escola como um campo de formação e produção do saber prático, essencial ao profissional docente. A articulação entre a universidade e a escola e, sobretudo, entre o ensino e a pesquisa sobre a prática docente, são os principais atributos para uma formação de qualidade presentes na perspectiva do PIBID.

\section{As contribuições do programa}

Desvendar as principais possibilidades, os limites e os efeitos diversos do PIBID, ainda que sob a perspectiva de determinado grupo, é uma prática que tem se mostrado válida e bastante promissora para a geração de conhecimentos sobre a validade social e educacional do programa (GATTI; BARRETO; ANDRÉ, 2011). Isso posto, este estudo reúne um conjunto de dados coletados e organizados com o intuito de apresentar as potencialidades do PIBID no processo de qualificação e encaminhamento de futuros professores à docência, e suas influências na qualidade da educação.

Em 2009, o subprojeto 4 do curso de Pedagogia de uma universidade pública do interior paulista recebe aprovação da CAPES e passa a ser implementado no início de 2010. Composto por um grupo de 20 bolsistas distribuídos em 2 escolas da rede municipal de ensino, o enfoque desse subprojeto consistiu em inserir os licenciandos, de maneira orientada, nas atividades concretas do professor, tanto naquelas de sala de aula quanto em outras que o professor realiza fora dela. O plano teve ainda a intenção de colaborar com o próprio supervisor e com os colegas da escola, no sentido de lhes prover formação para as necessidades que eles apresentam no seu exercício profissional. Assim, se estabeleceu como principal meta instaurar nos alunos bolsistas a percepção de que a formação se faz, em grande parte, nos embates com a prática e a partir de necessidades e, nos professores supervisores e demais docentes, a mentalidade de que a formação permanente é também de sua responsabilidade e que ela se dá na medida em que procura parcerias para resolver problemas colocados pela prática.

A proposta inicial do subprojeto explicita uma preocupação tanto com a formação inicial quanto com a formação em serviço dos professores que atuam nas escolas. Esse estratégico delineamento mostra-se essencial se pensarmos no quão cristalizadas tendem a ser as práticas dos professores que exercem a função há muitos anos e na questão da qualidade do que é ensinado por eles.

O artigo que reúne dados de entrevista com os bolsistas do subprojeto em questão traz, entre outros aspectos, informações sobre a relevância do programa aos professores em exercício:

\footnotetext{
4 O subprojeto em questão foi nomeado: O processo de formação de licenciandos: ações conjuntas da Universidade e da Escola de Educação Básica.
} 


\section{-Revista de Iniciação à Docência, v.6, n.2, 2021- Publicação: dezembro, 2021 - ISSN 2525-4332}

[...] o bolsista leva o frescor de alguém em formação e o professor passa toda a sua sabedoria adquirida ao longo dos anos de ofício. (Relato do bolsista B3, concedido para as autoras). (SOUZA; LONGHIN, 2012, p. 8).

[...] levamos a esses professores uma bagagem a mais de teorias que podem ser pensadas para espelhamento de uma prática. $O$ professor pode buscar o apoio do bolsista e junto com ele buscar planejar atividades, procurando atingir as finalidades do ensino. (Relato do bolsista B5, concedido para as autoras). (SOUZA; LONGHIN, 2012, p. 9).

As falas dos licenciandos são reforçadas pelos professores supervisores que, ao acompanharem a rotina do programa no interior das escolas parceiras, notam seus resultados nos trabalhos dos professores. Em registros de atas de reuniões, localiza-se nos relatos dos supervisores a percepção de que o envolvimento dos bolsistas na elaboração de atividades é o ponto forte da iniciativa PIBID, uma vez que convoca os professores a renovarem suas práticas.

Nos relatos descritos, pôde-se identificar a consciência de que na sala de aula encontra-se um conjunto de elementos de natureza social, econômica, cultural, histórica, política, científica, metodológica e psicológica, e que cabe ao professor ter um bom domínio de todos eles para poder articulá-los de maneira consistente, contextual, dinâmica e não rotineira.

Por se tratar de um subprojeto de Pedagogia, curso que habilita para a docência na Educação Infantil e nos anos iniciais do Ensino Fundamental, as ações práticas dos bolsistas foram voltadas, fundamentalmente, às estratégias e métodos de alfabetização. Bolsistas relataram em reuniões o grande desafio que é encontrar formas eficazes de ensinar os princípios básicos da leitura e da escrita, sobretudo às crianças que apresentam mais dificuldades. Segundo eles, esse desafio nunca havia sido enfrentado diretamente nos estágios supervisionados, e tampouco percebido no estudo das disciplinas curriculares. Foi necessário o contato com a realidade escolar e a possibilidade de realizar intervenções práticas, previamente planejadas, para que os alunos bolsistas sentissem a dimensão do que é a profissão docente.

Acho que antes eu não tinha uma visão do macro do sistema educativo. Como eu estava só nos estágios, tinha a impressão de que ser professor é estar ali na sala de aula ensinando e pronto. Eu não parava para pensar na questão de planejamento que se tem que fazer para dar uma boa aula. Essa visão do trabalho do professor fora da sala de aula também foi fundamental e eu não tinha clareza disso antes de entrar no PIBID (Relato do bolsista B1). (SOUZA; 2014, p. 118).

A preparação das aulas, das provas, de atividades adaptadas, de relatórios, dentre tantas outras atividades que caracterizam o trabalho do professor também puderam ser acompanhadas de perto, e essa oportunidade eu não tive durante os estágios obrigatórios do curso. Então eu posso dizer que o que mudou é que antes eu não imaginava o que era a atuação docente em seus mínimos detalhes e nas atividades mais cotidianas, e agora isso tudo fica claro para mim (Relato do bolsista B3). (SOUZA, 2014, p. 119). 
Estas colocações vão ao encontro dos resultados da pesquisa de Guarnieri (2005), com professores iniciantes, ao afirmar que o exercício da docência é condição para consolidar o processo de tornar-se professor na medida em que possibilita articulação entre os conhecimentos teóricos da formação com os do contexto escolar e da atuação prática em sala de aula.

Nos relatos também foram evidenciadas algumas dificuldades e os bolsistas as atribuíram aos sinais de resistência por parte dos professores das escolas, sobretudo no início da implementação do programa:

No começo, ganhar a confiança da professora foi algo bem complicado, ela ainda não estava à vontade com a minha presença e nem mesmo entendia minha função em sala de aula. Com o tempo essa relação foi ficando mais estreita e consegui criar um laço de amizade com a professora. Hoje eu a ajudo no que é preciso e tenho o apoio dela na hora de aplicar as atividades que eu proponho (Relato do bolsista B2, concedido para as autoras). (SOUZA; LONGHIN, 2012, p. 6).

A resistência, entretanto, não deve ser compreendida à luz de julgamentos, pois apesar de representar um grande empecilho para a formação dos estagiários/ bolsistas, revela o descontentamento dos professores face às adaptações que têm de se submeter sem terem recebido uma preparação anterior. Esse assunto foge do escopo deste trabalho, mas é importante destacar que seu aprofundamento merece a atenção de estudiosos, uma vez que a literatura de pesquisa cuja contribuição se volte à questão da resistência docente nesse prisma é ainda incipiente.

A oportunidade de desenvolver e aplicar atividades e ver seus resultados refletidos na aprendizagem dos alunos, ainda que gradualmente e com exaustiva dedicação, foi um resultado que se destacou nos estudos analisados e representa para os bolsistas a fonte principal de satisfações. De acordo com os bolsistas, o rendimento dos alunos foi significativamente elevado se considerarmos o período de vigência do PIBID nas escolas, e atribuem tal êxito à aproximação dos alunos aos conteúdos escolares pelo desenvolvimento de atividades lúdicas e contextualizadas.

A título de exemplo, resgato nos Relatórios produzidos pelas bolsistas uma atividade realizada pela bolsista B1. Segue a descrição das etapas de tal atividade:

o desenvolvimento da atividade foi conduzido de acordo com as seguintes etapas: a) leitura da história "Chapeuzinho Vermelho", com a utilização de ilustrações e capuz de pano na cor vermelha, frequentemente usado pela personagem principal do conto; b) o reconto da história pelos alunos; c) a análise do episódio "Chapeuzinho Vermelho 2" da Turma da Mônica; d) leitura do livro "Chapeuzinho Amarelo", de Chico Buarque; e) discussões orais acerca das semelhanças e diferenças entre as diferentes versões apresentadas do conto; f) criação pelos alunos de um final diferente para o conto original; g) para finalizar, foi feita uma dobradura da Chapeuzinho e a elaboração de uma lista dos alimentos que haviam em sua cesta. Essa atividade teve a finalidade de despertar nos alunos a curiosidade e estimular o gosto, o prazer pela leitura, através da análise das releituras do clássico Chapeuzinho Vermelho. Avaliando a atividade constatamos a animação e motivação dos alunos durante todas as 


\section{-Revista de Iniciação à Docência, v.6, n.2, 2021- Publicação: dezembro, 2021 - ISSN 2525-4332}

etapas, nos mostrando que muitas vezes a maneira como se conta histórias influencia no interesse e no gosto da criança pela leitura (B1, Relatório Final 2010). (SOUZA, 2014, p. 103).

Notou-se que esse tipo de atividade contempla o almejado no do subprojeto, uma vez que envolve a elaboração e realização de atividades, a intencionalidade, a clareza dos objetivos e a apresentação de resultados. Além disso, ao se destacar a parceria entre a bolsista e a professora da sala de aula e o desenvolvimento de atividades a partir de necessidades coletivas, cumpriu-se também uma das metas mais buscadas pelo PIBID estabelecidas nos editais do Programa, que institui promover experiências metodológicas e práticas docentes "que se orientem para a superação de problemas identificados no processo ensino-aprendizagem” (CAPES, 2009).

Diante da breve análise de relatos aqui tecida, nota-se a existência de um conceito de qualidade que se manifesta muito mais nas práticas cotidianas do que em avaliações externas. Conceito este pautado no desenvolvimento diário dos alunos, na incorporação de um conjunto de aptidões que não se limitam ao preenchimento de alternativas corretas em uma avaliação, na transformação das práticas dos professores, na produção de conhecimento para e com os alunos, e em outros indicadores que só podem ser identificados em campo. Um conceito que se efetiva gradativamente tanto no âmbito da sala de aula como fora dela, nas atividades que permeiam a educação.

\section{Considerações finais}

À guisa de conclusão, tendo em vista o panorama descritivo e analítico explicitado neste artigo, destacam-se, a seguir, alguns aspectos concernentes às influências do PIBID no delineamento de um conceito e da efetividade da qualidade em educação:

a) O conceito de qualidade implícito nas ações do PIBID envolve, em essência, fatores de natureza subjetiva, tais como a motivação dos alunos e dos professores com relação ao processo ensino-aprendizagem, a existência de relações interpessoais harmoniosas, as expectativas de futuros professores para o início da carreira, a transformação da prática dos professores em exercício, a qualificação da formação docente pela relação profícua entre universidade e escola básica;

b) Em detrimento à visão tradicional, que visa identificar e quantificar o desempenho das escolas através de avaliações externas, na proposta do PIBID a qualidade na educação, enquanto prática social concreta, se efetiva à medida que os agentes, qualitativamente, a constroem e a percebem no desenvolvimento de suas ações;

c) O investimento e valorização do magistério é condição fundamental para a melhoria da qualidade da Educação Básica. Assim sendo, a inserção significativa de licenciandos no universo escolar, de maneira organizada, orientada e que privilegie a 
parcela prática de formação, faz-se imprescindível para que haja uma elevação da qualidade da atuação de futuros professores;

d) A satisfação, a parceria e o engajamento ativo dos licenciandos e dos professores no processo político-pedagógico e, principalmente, no processo de ensinoaprendizagem são fatores de fundamental importância para a melhoria do desempenho escolar e sucesso dos alunos;

e) Embora as normatizações brasileiras definam condições intra e extraescolares inegavelmente importantes para buscarmos melhorias na qualidade, considerar as representações dos protagonistas da educação que atuam diretamente com o ensino, ou seja, os professores, os estagiários e os bolsistas de programas institucionais, para que se constituam impressões mais realistas, certamente seria uma estratégia eficiente e que poderia trazer dados concretos, sejam eles locais e particulares, ou amplos e suscetíveis a generalizações.

\section{Referências}

ALARCÃO, Isabel. Reflexão crítica sobre o pensamento de D. Schön e os programas de formação de professores. In: ALARCÃO, Isabel (org.). Formação Reflexiva de Professores: Estratégias de Supervisão. Porto: Porto Editora, 1996, p. 9-39.

ANDRÉ, Marli Eliza Dalmazo Afonso de Políticas e programas de apoio aos professores iniciantes no Brasil. Cadernos de Pesquisa. São Paulo, vol. 42, n. 145, p. 112-129, 2012.

BRASIL, Constituição de 1988. Constituição da República Federativa do Brasil. Brasília: Senado Federal, 1988.

BRASIL, Lei $n^{\circ}$ 9.394, de 20 de dezembro de 1996. Estabelece as diretrizes e bases da educação nacional. Diário Oficial da União. Brasília: Casa Civil da Presidência da República, 1996.

BRASIL, Ministério da Educação. Plano de Desenvolvimento da Educação: razões, princípios e programas. Brasília: MEC, 2007.

BRASIL, Ministério da Educação. Proposta de diretrizes para a formação inicial de professores da Educação Básica em cursos de nível superior. Brasília, DF, 2000.

BRASIL. Portaria Gab n 45, de 12 de março de 2018. Dispõe sobre a concessão de bolsas e o regime de colaboração no Programa de Residência Pedagógica e no Programa Institucional de Bolsa de Iniciação à Docência. SEI/CAPES, 2018.

CAPES. Diretoria de Educação Básica Presencial (DEB) PIBID: Relatório de gestão 20092011, 2012.

CURY, Carlos Jamil. Qualidade Em Educação. Nuances: estudos sobre Educação, ano XVII, vol. 17, n. 18, p. 15-31, jan./dez. 2010.

DEIMLING, Natalia Neves Macedo; REALI, Aline Maria De Medeiros Rodrigues. PIBID: considerações sobre o papel dos professores da educação básica no processo de iniciação à docência. Educ. rev., Belo Horizonte, v. 36, 2020.

GATTI, Bernardete Angelina; BARRETO, Elba Siqueira de Sá; ANDRÉ, Marli Eliza Dalmazo 
Afonso de. Políticas docentes no Brasil: um estado da arte. Brasília: UNESCO, 2011.

GATTI, Bernardete Angelina; NUNES, Marina Muniz Rossa (Orgs.). Formação de professores para o ensino fundamental: instituições formadoras e seu currículo; relatório de pesquisa. São Paulo: Fundação Carlos Chagas; Fundação Vitor Civita, 2008.

GUARNIERI, Maria Regina. O início na carreira docente: pistas para o estudo do trabalho do professor. In: GUARNIERI, Maria Regina (Org.). Aprendendo a ensinar: o caminho nada suave da docência. 2 ed. Campinas: Autores Associados, 2005, p. 5-23.

NEVES, Carmen Moreira de Castro. A Capes e a formação de professores para a educação básica. Revista RBPG, Brasília, vol. 8, p. 353 - 373, mar. 2012.

NÓVOA, António. Para uma formação de professores construída dentro da profissão. Revista Educación. Madrid, Ministerio de Educación, n. 350, p. 1-10, set./dez, 2009.

PERRENOUD, Philippe. Práticas pedagógicas, profissão docente e formação: perspectivas sociológicas. Lisboa: Dom Quixote, 1993.

PIMENTA, Selma Garrido. Professor Reflexivo: construindo uma crítica. In: PIMENTA, Selma Garrido (org.). Professor reflexivo no Brasil: gênese e crítica de um conceito. 4 ed. São Paulo: Cortez, 2006.

SCHÖN, Donald. Educando o profissional reflexivo: um novo design para o ensino e a aprendizagem. Trad. Roberto Cataldo Costa. Porto Alegre: Artes Médicas Sul, 2000.

SOUZA, Nathália Cristina Amorim Tamaio de; LONGHIN, Rayana Silveira Souza. A constituição da identidade e dos saberes docentes: o projeto PIBID em foco. CAMINE: Caminhos da Educação, vol. 4, n. 2, p. 1-12, 2012.

SOUZA, Nathália Cristina Amorim Tamaio de. As ações do PIBID Pedagogia e suas relações com o preparo prático para a docência nos anos iniciais do Ensino Fundamental. 2014. 154 f. Dissertação (Mestrado) - Universidade Estadual Paulista, Araraquara, 2014.

ZEICHNER, Kenneth. Para além da divisão entre professor-pesquisador e pesquisadoracadêmico. In: GERALDI, Corinta Maria Grisolia et al. Cartografias do trabalho docente: professor(a)-pesquisador(a). Campinas: Mercado de Letras, 1998, p. 207-236.

ZEICHNER, Kenneth. Repensando as conexões entre formação na universidade e as experiências de campo na formação de professores em faculdades e universidades. Educação. Santa Maria, RS, v. 35, n. 3, p. 479-504, 2010. 